\title{
The predictors of COVID-19 mortality among health systems and Global Health Security parameters: An ecological study across 203 countries.
}

Sutapa Neogi ( $\sim$ drsutapa1@gmail.com )

International Institute of Health Management Research - New Delhi https://orcid.org/0000-0002-2173966X

Shivam Pandey

AllMS: All India Institute of Medical Sciences

Preetha GS

IIHMR New Delhi: International Institute of Health Management Research - New Delhi

\section{Sumant Swain}

International Institute of Health Management Research - New Delhi

\section{Research Article}

Keywords: COVID, health systems, resilience, global health security, health expenditure

Posted Date: November 12th, 2021

DOI: https://doi.org/10.21203/rs.3.rs-1046091/v1

License: (9) This work is licensed under a Creative Commons Attribution 4.0 International License. Read Full License 


\section{Abstract}

Background: Health systems responsiveness is the key to addressing infectious disease threats such as pandemics. The paper outlines an assessment of health systems resilience by exploring the association of health systems and Global Health Security (GHS) parameters with case load and mortality resulting from COVID-19 across 203 countries using an ecological design.

Methodology: Correlation analysis was performed to assess the relationship of each of the indicators with COVID 19 cases and deaths per million population. Stepwise multiple regression models were developed to determine the predictors of COVID-19 cumulative cases and deaths per million population separately.

Results: Global health security indicators seemed to have a strong association when analyzed individually but those did not necessarily translate into less burden of cases or deaths in the multivariable analysis. The predictors of cumulative deaths per million population included general government expenditure on health as a proportion of general government expenditure, responsiveness of the system to prevent the emergence and release of pathogens and governance related voice and accountability.

Conclusion: To conclude, health financing parameters and preventive activities with regard to emergence of pathogens were better predictors of cumulative COVID-19 cases and deaths per million population compared to other health systems and global health security indicators.

\section{Key Messages:}

- Health financing parameters are better predictors of cumulative COVID-19 cases and deaths per million population compared to other health systems and global health security indicators.

- More robust and valid indicators are required to assess the performance of health system.

\section{Introduction:}

COVID-19, caused by the novel SARS-CoV-2 is the worst catastrophe in this century that affected more than 228 million people and caused more than 4.6 million deaths globally[1]. The proportion of cases was maximum in the Americas (39\%), followed by Europe (30\%), South-East Asia (19\%), Eastern Mediterranean (7\%), Western Pacific (3\%), and Africa (3\%) among WHO regions. Similar trend was observed regarding distribution of deaths, with Americas leading with $46 \%$ of the burden followed by Europe (28\%), South-East Asia (14\%), Eastern Mediterranean (6\%), Western Pacific (2\%), and Africa (3\%) [1]. The health systems have been struggling to play a vital role to minimise the case load and morbidity by instituting preventive measures and avert mortality by providing appropriate case management.

Health system is defined as comprising all the resources, organizations, and institutions, which produce interdependent actions aimed principally at improving, maintaining, or restoring health. Health system responsiveness displays the strength and preparedness of nations to prevent, protect against, respond to, 
recover from health emergencies, help them cope, and not be overwhelmed by the sudden and disproportionate increase in the demand of health facilities[2]. The performance of health systems is gauged by assessing the select parameters of its building blocks(encompassing service delivery, health workforce, medical products, health financing, health information system, leadership, and governance), within the overarching goals of better health, responsiveness to the expectations of the population, and equity of financial contribution with protection against financial risk. In order to combat any public health crises, a set of activities are required to minimize the danger and impact of acute public health events that endanger the collective health of populations living across geographical regions and international boundaries, collectively embedded under Global public health security measures. The parameters of health security covers prevention of emergence or release of pathogens, early detection and reporting for epidemics of potential international concern, rapid response to and mitigation of the spread of an epidemic, sufficient and robust health system to treat the sick and protect health workers, commitment to improving national capacity, financing and adherence to norms and overall risk environment and country vulnerability to biological threats. These parameters, too fall under the ambit of health systems, that are aimed to improve epidemic detection, preparedness, response, and case management.

A preliminary analysis was done to assess the strength of health systems of select countries and their capacities to respond to pandemic threats using WHO and Global Health Security frameworks, which had exposed the weaknesses of global health systems preparedness, the inability to respond timely in most countries, and the ineffectiveness of policy responses in many instances[3].

Reports have stated that a country's health system is the first line of defense in the face of any crisis, and if the system is not resilient, it will be overwhelmed and collapse, exacerbating the health impact and adding to inequality. Countries such as Germany, New Zealand, South Korea, Taiwan Province of China, and Vietnam have demonstrated resilience in their health systems and therefore could tackle COVID19 better[4].

We therefore undertook a more comprehensive analysis on health systems resilience by exploring the association of health systems and Global Health Security (GHS) parameters with case load and mortality resulting from COVID-19across all countries. The objective of the analysis is to identify the health systems and GHS factors that are most predictive of mortality due to COVID-19 in all countries across WHO regions.

\section{Materials And Methods:}

The study followed an ecological design with country as the unit of analysis. Secondary data of 203 countries across all WHO region countries, available in the public domain were analyzed. The WHO health systems framework and Global Health Security (GHS) parameters formed the explanatory variables[5, 6]. The performance of each building block was assessed with respect to the standardized indicators proposed by the WHO[5].A list of indicators with respect to GHS has been drawn from the existing literature[6]. 


\section{Box 1: List of health systems indicators used in the study as explanatory variables}

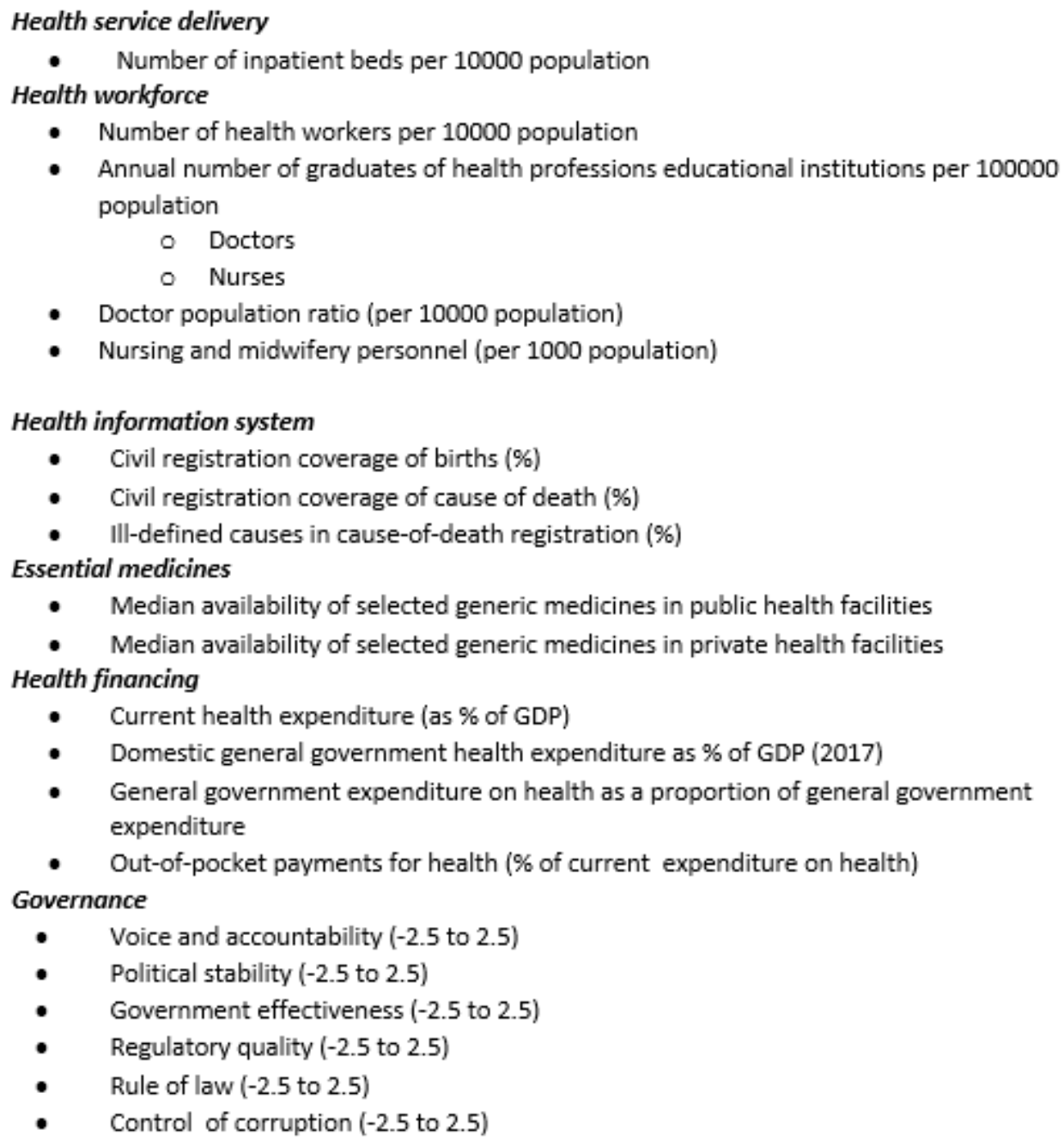

- Annual number of graduates of health professions educational institutions per 100000 population

- Doctors

- Nurses

- Doctor population ratio (per 10000 population)

- Nursing and midwifery personnel (per 1000 population)

\section{Health information system}

- $\quad$ Civil registration coverage of births (\%)

- $\quad$ Civil registration coverage of cause of death (\%)

- $\quad$ Ill-defined causes in cause-of-death registration (\%)

\section{Essential medicines}

- Median availability of selected generic medicines in public health facilities

- Median availability of selected generic medicines in private health facilities Health financing

- Current health expenditure (as \% of GDP)

- Domestic general government health expenditure as \% of GDP (2017)

- General government expenditure on health as a proportion of general government expenditure

- $\quad$ Out-of-pocket payments for health (\% of current expenditure on health)

\section{Governance}

- Voice and accountability ( -2.5 to 2.5$)$

- Political stability ( -2.5 to 2.5$)$

- Government effectiveness (-2.5 to 2.5 )

- Regulatory quality ( -2.5 to 2.5 )

- Rule of law (-2.5 to 2.5)

- Control of corruption ( -2.5 to 2.5 )

Global health security indicators: (all out of 100)

- Prevention of emergence or release of pathogens

- Early detection and reporting for epidemics of potential international concern

- Rapid response to and mitigation of the spread of an epidemic

- Sufficient and robust health system to treat the sick and protect health workers

- Commitment to improving national capacity, financing and adherence to norms

- Overall risk environment and country vulnerability to biological threats

Other indicators (\%)

- Female literacy rate

- Proportion of people aged 60 years or more

- Proportion of people below poverty line

For the purpose of analysis, outcome indicators includedCOVID-19 cumulative cases per one million population and cumulative deaths per one million population as on 1 November 2020, 10 am CEST, for every country. The underlying assumption behind considering the cumulative number of cases is that 
timely initiation of measures such as isolation of patients in hospitals or home which indirectly is related to dependent on numbers of doctors, nurses and ability to make more beds available will dampen the spread of infection. A sensitive health system will be able to mobilize its resources to isolate, manage and treat COVID-19patients efficiently to avert deaths, thus, justifying cumulative deaths as a key outcome variable.

The data on cumulative cases and deaths were obtained from WHO-Weekly epidemiological update[1]. The purpose of this restriction was to have data that were not affected by immunization. We presumed that population level vaccination drive was initiated in phases after October 2020 in different parts of the world.

\section{Statistical Analysis}

The analysis was performed by considering all countries combined. It focused on exploring the predictors of COVID-19 cumulative cases and deaths per million population. Descriptive characteristics of the health system factors for all the countries have been presented. Correlation analysis was performed using Pearson's correlation, and Spearman's rank correlation, as appropriate. Subsequently, stepwise multiple linear regression models were developed to determine the predictors of COVID-19 cumulative cases and deaths per million population separately. Variables that had a strong correlation in bivariate analysis, had about $80 \%$ data available and seemed to be a plausible explanation for COVID-19 infection and deaths were considered in the models. All analyses were performed in STATA version 16 (StataCorp, College Station,Texas) and SPSS version 21.

\section{Results:}

Data compiled from WHO repository reflected incompleteness of data for several countries. Missing data were more for indicators related to health workforce and essential medicines. These missing variables were from different regions except South East Asia. (Table 1) 
Table 1

Descriptive characteristics of health systems factors for countries

\begin{tabular}{|c|c|c|c|c|c|}
\hline Variable & $\mathbf{N}$ & $\begin{array}{l}\text { Mean } \\
\text { value }\end{array}$ & Min & Max & $\begin{array}{l}\text { Std. } \\
\text { Dev. }\end{array}$ \\
\hline \multicolumn{6}{|l|}{ Health service delivery } \\
\hline Number of inpatient beds per 10000 population* & 159 & 26.25 & 1 & 143 & 23.98 \\
\hline \multicolumn{6}{|l|}{ Health workforce } \\
\hline Number of health workers per 10000 population* & 34 & 54.39 & 5.7 & 151.9 & 45.89 \\
\hline $\begin{array}{l}\text { Annual number of graduates (Doctors) of health } \\
\text { professions educational institutions per } 100000 \\
\text { population** }\end{array}$ & 36 & 14.61 & 3.3 & 56 & 8.73 \\
\hline $\begin{array}{l}\text { Annual number of graduates (Nurses) of health } \\
\text { professions educational institutions per } 100000 \\
\text { population** }\end{array}$ & 34 & 45.02 & 14 & 101 & 24.88 \\
\hline Doctor population ratio (per 10000 pop) \# & 185 & 17.78 & 0.008 & 85.5 & 17.15 \\
\hline Nursing and midwifery personnel (per 10000 pop) \#\# & 185 & 42.75 & 0.6 & 201.609 & 43.19 \\
\hline \multicolumn{6}{|l|}{ Health information } \\
\hline Civil registration coverage of births (\%) & 170 & 84.16 & 2.7 & 100 & 23.85 \\
\hline Civil registration coverage of cause of death (\%) & 116 & 83.35 & 0 & 100 & 24.82 \\
\hline III defined causes in cause of death registration (\%) & 91 & 12.75 & 1.68 & 46 & 9.55 \\
\hline \multicolumn{6}{|l|}{ Essential medicines^ } \\
\hline $\begin{array}{l}\text { Median availability of selected generic medicines in } \\
\text { public health facilities (2007-13) }\end{array}$ & 39 & 56.13 & 0 & 100 & 28.69 \\
\hline $\begin{array}{l}\text { Median availability of selected generic medicines in } \\
\text { private health facilities }\end{array}$ & 42 & 64.17 & 2.8 & 100 & 25.18 \\
\hline \multicolumn{6}{|l|}{ Health Financing } \\
\hline Current health expenditure (as \% of GDP) (2017)\#\#\# & 181 & 6.63 & 1.2 & 17.1 & 2.85 \\
\hline $\begin{array}{l}\text { Domestic general government health expenditure as \% } \\
\text { of GDP (2017)\$ }\end{array}$ & 183 & 14 & 0.4 & 89.4 & 20.12 \\
\hline $\begin{array}{l}\text { General government expenditure on health as a } \\
\text { proportion of general government expenditure @ }\end{array}$ & 135 & 11.43 & 1.4 & 26.9 & 5.09 \\
\hline $\begin{array}{l}\text { Out-of-pocket payments for health (\% of current } \\
\text { expenditure on health)@@ }\end{array}$ & 184 & 31.22 & 0.1 & 80.95 & 19.22 \\
\hline $\begin{array}{l}\text { Global health security indicators (all scores out of } \\
100) \$ \$\end{array}$ & & & & & \\
\hline
\end{tabular}




\begin{tabular}{|c|c|c|c|c|c|}
\hline Variable & $\mathbf{N}$ & $\begin{array}{l}\text { Mean } \\
\text { value }\end{array}$ & Min & Max & $\begin{array}{l}\text { Std. } \\
\text { Dev. }\end{array}$ \\
\hline Prevention of emergence or release of pathogens & 191 & 34.6 & 1.9 & 83.1 & 17.07 \\
\hline $\begin{array}{l}\text { Early detection and reporting for epidemics of potential } \\
\text { international concern }\end{array}$ & 191 & 42.06 & 2.7 & 98.2 & 23.98 \\
\hline $\begin{array}{l}\text { Rapid response to and mitigation of the spread of an } \\
\text { epidemic }\end{array}$ & 191 & 38.68 & 16 & 91.9 & 15.24 \\
\hline $\begin{array}{l}\text { Sufficient and robust health system to treat the sick } \\
\text { and protect health workers }\end{array}$ & 191 & 26.67 & 0.3 & 73.8 & 17.27 \\
\hline $\begin{array}{l}\text { Commitment to improving national capacity, financing } \\
\text { and adherence to norms }\end{array}$ & 191 & 47.97 & 23.3 & 85.3 & 12.76 \\
\hline $\begin{array}{l}\text { Overall risk environment and country vulnerability to } \\
\text { biological threats }\end{array}$ & 191 & 54.65 & 6.2 & 87.9 & 17.14 \\
\hline Overall score- global health security & 191 & 40.17 & 16.2 & 83.5 & 14.79 \\
\hline \multicolumn{6}{|l|}{ Socio demographic factors } \\
\hline Female literacy rate & 81 & 92.27 & 55 & 100 & 10.71 \\
\hline Proportion of people aged 60 years or more & 104 & 30.56 & 0.18 & 100 & 28.55 \\
\hline Proportion of people below poverty line & 87 & 19.96 & 0.06 & 61.9 & 12.02 \\
\hline \multicolumn{6}{|l|}{ Governance } \\
\hline Voice \& Accountability & 137 & 0.19 & -2.2 & 1.73 & 0.98 \\
\hline Political Stability & 139 & 0.12 & -3 & 1.61 & 0.98 \\
\hline Government Effectiveness & 137 & 0.21 & -2.24 & 2.23 & 0.99 \\
\hline Regulatory Quality & 137 & 0.18 & -2.34 & 2.21 & 1 \\
\hline Rule of Law & 137 & 0.2 & -2.33 & 2.05 & 1 \\
\hline Control of Corruption & 137 & 0.18 & -1.8 & 2.21 & 1.02 \\
\hline
\end{tabular}




\begin{tabular}{|l}
\hline Variable \\
*https://www.who.int/workforcealliance/knowledge/resources/GHWA-a_universal_truth_report.pdf \\
**OECD library https://data.oecd.org/healthres/medical-graduates.htm \\
\# https://apps.who.int/gho/data/node.main.HWFGRP_0020?lang=en \\
\#\# https://apps.who.int/gho/data/node.main.HWFGRP_0040?lang=en \\
\#\#\#https://apps.who.int/gho/data/node.main.GHEDCHEGDPSHA2011?lang=en \\
\$ https://apps.who.int/gho/data/node.main.GHEDGGHEDGDPSHA2011?lang=en \\
@ https://apps.who.int/gho/data/node.main.GHEDGGHEDGGESHA2011?lang=en \\
@@ https://apps.who.int/gho/data/node.main.GHEDOOPSCHESHA2011?lang=en \\
^https://apps.who.int/gho/data/node.main.488?lang=en \\
\$ https://www.ghsindex.org/
\end{tabular}

The first part of the analysis assessed the correlation of health system variables with cumulative cases per million population. (Table 2) Global health security indicators seemed to have a strong association when analysed individually but those did not necessarily translate into less burden of cases or deaths in the multivariable analysis. Correlational analysis of health system indicators with COVID-19cases and deaths revealed a consistent association with health financing parameters. 
Table 2

Correlation of health systems and GHS factors with cumulative cases and deaths per million population

Variable

$\begin{array}{ll}\text { Correlation coeff with } & \begin{array}{l}\text { Correlation coeff with } \\ \text { Cumulative } \\ \text { Ceaths/million pop }\end{array} \\ \text { pop } & \end{array}$

n Spearman's $P$ Spearman's $P$ value rho value rho

Health service delivery

Number of inpatient beds per 10000

$143 \quad 0.3283$

0.0001

0.2475

0.0029

population

Health workforce

Number of health workers per 10000 population

$33 \quad 0.3657$

0.0364

0.3565

0.0417

Annual number of graduates (Doctors) of health professions educational

34

0.1264

0.4762

0.104

0.5583

institutions per 100000 population

Annual number of graduates (Nurses) of

$33 \quad-0.0985$

$0.5856 \quad-0.3128$

0.0763

health professions educational

institutions per 100000 population

Doctor population ratio (per 10000 pop)

$165 \quad 0.5911$

$<0.001$

0.5465

$<0.001$

Nursing and midwifery personnel (per 10000 pop)

$164 \quad 0.5373$

$<0.001$

0.4365

$<0.001$

Health information

Civil registration coverage of births (\%)

Civil registration coverage of cause of death $(\%)$

III defined causes in cause of death registration (\%)

15

109

0.5829

$<0.001$

0.5175

$<0.001$

Essential medicines

Median availability of selected generic

$38 \quad 0.2757$

0.0939

0.2084

0.2092

medicines in public health facilities (2007-

13)

Median availability of selected generic medicines in private health facilities

$41 \quad 0.2986$

0.0579

0.2442

0.1238

Health Financing

Current health expenditure (as \% of GDP) (2017)

$162 \quad 0.3443$

$<0.001$

0.3984

$<0.001$ 
Variable

Domestic general government health expenditure as \% of GDP (2017)

General government expenditure on health as a proportion of general government expenditure

Out-of-pocket payments for health (\% of current expenditure on health)

Global health security indicators (all scores out of 100)

Prevention of emergence or release of pathogens

Early detection and reporting for epidemics of potential international concern

Rapid response to and mitigation of the spread of an epidemic

Sufficient and robust health system to treat the sick and protect health workers

Commitment to improving national capacity, financing and adherence to norms

Overall risk environment and country vulnerability to biological threats

Overall score- global health security

Socio demographic factors

Female literacy rate

Proportion of people aged 60 years or more

Proportion of people below poverty line

Governance

Voice \& Accountability

Political Stability

Government Effectiveness

Regulatory Quality
Correlation coeff with Cumulative cases/million pop

163

123

0.4017

164

0.2321

0.0029

$<0.001$

0.4384

$<0.001$

Correlation coeff with Cumulative deaths/million pop

$0.3133<0.001$

170

0.4334

$<0.001$

0.4344

$0<0.001$

170

0.3283

$<0.001$

0.3513

$<0.001$

$0.0029 \quad-0.1303$

0.0963

$-0.2315$

$$
<0.001
$$

170

0.3347

170

0.4776

170

0.1145

0.137

0.1504

0.0502

$<0.001$

0.3191

$<0.001$

$<0.001$

0.4471

$<0.001$

$170 \quad 0.5826$

$<0.001$

0.4631

$<0.001$

$170 \quad 0.4637$

$<0.001$

0.4424

$<0.001$ $\begin{array}{ll}76 & 0.29\end{array}$

$98 \quad-0.2912$

78

$-0.1085$

0.3444

0.1069

0.3515

0.1432 $<0.001$

$0.0036 \quad-0.4059$
0.1069

0.0016

0.2485

0.0052

$125 \quad 0.279$

$0.083-0.049$

0.5855

126

0.1551

0.0001

0.1833

0.0416

$124 \quad 0.3359$

$<0.001$

0.2706

0.0024 


\begin{tabular}{|llllll|}
\hline Variable & \multicolumn{2}{l|}{$\begin{array}{l}\text { Correlation coeff with } \\
\text { Cumulative cases/million } \\
\text { pop }\end{array}$} & \multicolumn{3}{l|}{$\begin{array}{l}\text { Correlation coeff with } \\
\text { Cumulative } \\
\text { deaths/million pop }\end{array}$} \\
\hline Rule of Law & 124 & 0.32 .3 & 0.0003 & 0.1277 & 0.1576 \\
\hline Control of Corruption & 124 & 0.2711 & 0.0023 & 0.0957 & 0.2903 \\
\hline
\end{tabular}

Among all the factors studied, those predictive of cumulative cases per million population included infrastructural, human resource and financing parameters such as adequate inpatient beds health workers, expenditure on health as percent of GDP and also GHS parameters as prevention of emergence of pathogens and also early detection and reporting of epidemics of international concern. Achieving Global health security parameters and numbers of doctors or health workers did not predict less numbers of cases. (Table 3)

Table 3

Multivariable analysis on health systems and GHS predictors of cumulative COVID-19cases per million population)

$\begin{array}{ll}\text { Variables } & \text { Regression coefficient }(95 \% \\ \text { Cl); } p \text { value }\end{array}$

Number of inpatient beds per 10000 population

Number of health workers per 10000 population

Doctor population ratio (per 10000 pop)

Overall score- global health security

Civil registration coverage of births (\%)

Prevention of emergence or release of pathogens

Domestic general government health expenditure as \% of GDP (2017)

General government expenditure on health as a proportion of general government expenditure

Early detection and reporting for epidemics of potential international concern
$-118.39(-150.86,-85.92)$; $<0.001$

$70.11(10.43,129.78) ; 0.025$

364.8 (297.88, 431.72); $<0.001$

569.16 (169.43, 968.89);

0.01

$-98.77(-162.02,-35.53)$;

0.006

$-273.81(-464.31,-83.32)$;

0.009

$-102.6(-163.4,-41.79) ; 0.003$

340.66 (93.71, 587.61); 0.01

$-231.52(-378.88,-84.17)$; $<0.001$

The predictors of cumulative deaths per million population included general government expenditure on health as a proportion of general government expenditure, responsiveness of the system to prevent the emergence and release of pathogens and governance related voice and accountability. (Table 4) Interestingly, number of cases was weakly correlated with number of deaths. Voice and accountability as a positive predictor may suggest better reporting of deaths due to better governance. 
Table 4

Multivariable analysis on health systems and GHS predictors of COVID-19deaths per million population

Variables

-Regression coefficient $(95 \%$

$\mathrm{Cl})$; $\mathrm{p}$ value

General government expenditure on health as a proportion of general government expenditure

$-24.56(-39.43,-9.69) ; 0.003$

Cumulative cases per 1 million population

$0.01(0.004,0.019) ; 0.004$

Prevention of emergence or release of pathogens

$-12.39(-20.85,-3.93) ; 0.007$

Voice \& Accountability

$121.82(42.11,201.53) ; 0.005$

Rapid response to and mitigation of the spread of an epidemic

$17.39(8.81,25.97) ; 0.001$

Domestic general government health expenditureas \% of GDP (2017)

$8.85(5.53,12.18) ;<0.001$

Proportion of population aged more than 60 years showed a strong association with COVID-19cases and deaths in the unadjusted analysis but not when adjusted for health systems factors. Neither socio economic status reflected from the proportion of population below poverty line nor female literacy seemed to have any influence on the number of cases or deaths.

\section{Discussion:}

An ecological analysis of health systems indicators of 203 countries suggest that health financing parameters and preventive activities with regard to emergence of pathogens were better predictors of cumulative COVID-19 cases and deaths per million population compared to other health systems and global health security indicators.

A lot of scepticism surrounds the use of appropriate indicators and computation of health system indices[7]. Most of the criticism focusses on the technical aspects of constructing the composite index[8]. In several instances, validation exercises are conducted across countries before they are put to use. Health systems data utilize different approaches to collecting, systematising and communicating knowledge. Self reporting by Government yield data that are often biased and inaccurate. Such assessments are likely to give rise to erroneous results. For instance, the Global Health Security Indicators data relies on wide-ranging sources of data to feed into a uniform classification system that ranks different countries[9]. A study from 36 countries that assessed the preparedness to prevent, detect and respond to infectious disease threats showed that GHS is not predictive[10]. Our study also highlights similar findings.

Health systems performance is presumably the key determinant that should be held accountable for any public health crisis. Capacity of health systems is usually assessed according to its structure, the health expenditure concerning the GDP, some indicators of development of a country, as stand alone components or in combination. Increasing resources for National Health system are critical to improving 
health in developing countries. However, using existing resources more efficiently is accorded more importance than their mere availability. This is evident from a lack of appreciable differences observed between different health systems models such as the Beveridge model, the Bismarck model, the National Health Insurance (NHI) model, and the "Out-of-Pocket" model[11].

Universal health coverage (UHC) aims to provide access to essential health services to all population and provide protection against catastrophic health spending. A robust health financing system is the cornerstone to achieve UHC[12]. General government expenditure on health as a proportion of general government expenditure is a core indicator of health financing systems. This indicator contributes to understand the weight of public spending on health within the total value of public sector operations[5]. It includes not just the resources channelled through government budgets but also the expenditure on health by parastatals, extrabudgetary entities and notably the compulsory health insurance. It refers to resources collected and pooled by public agencies including all the revenue modalities.

Although per capita health spending has significantly increased worldwide, such gains are varied, and most increases in health spending and pooled health spending are concentrated among upper-middleincome and high-income countries rather than lower- middle-income and low-income countries[12]. Ensuring that all countries have sustainable pooled health resources is crucial to the achievement of $\mathrm{UHC}[12]$. Previous studies have explored how to translate health resources into achieving UHC by offering cost estimates for UHC attainment. Although such studies can be useful for initial planning purposes, they often fail to account for system inefficiencies and implementation challenges associated with programmatic scale-up. Moreover, measures of health-service costs are fundamentally different from quantification of the amount of total health spending needed to implement and sustain national health systems[12]. Countries that have closely aligned polices of UHC and GHS have fared relatively better[13].

Dissemination of information regarding performance of hospitals or providers, is important in ensuring the transparency and accountability of government spending and decision-making[14].It is important to focus on effective coverage for better understanding of benefits accrued from UHC[15]. The area of health financing calls for more research and understanding in order to mount an effective public health response during crises[16].

The pandemic has exerted enormous pressure on health systems around the world highlighting the sub optimal resilience of countries, even those that were labelled as strong by various assessments. This builds up a case for rethinking on the metrics that would be more reflective of the ground situation and would be more resilience relevant[2]. Resilience should embark upon the principles of absorptive, adaptive and transformative capacities[7]. Use of inappropriate indicators have masked the real situation and probably have instilled a false sense of confidence to face such global threats.

While resilience is a core concept in disaster risk reduction, its application to health systems is relatively new. It is high time that we start investigating not only on preparedness but on health systems strengthening[17]. Health-systems resilience, reflects an ability to adapt and respond and is, therefore, critical to assess[13]. A remodelled global health framework that envisages integration of UHC and GHS 
policies and approach, coupled with innovative and unified health financing, cross-sector resilience, equity and reliable indicators to measure those, offer an opportunity to strengthen health systems performance[13].

The analysis suffers from limitations in terms of missing data for certain variables from many countries. Indicators that were readily available for each health systems block was considered, most of which seemed to be proxy indicators. Also, the time frame for the latest data considered for this analysis varied between countries. However, we do not anticipate any gross deviation in country specific data so as to influence the results significantly. There are concerns around reporting of actual numbers of COVID-19 cases and deaths from many countries. Despite these limitations, the study has an advantage of providing a comprehensive analysis of health systems factors across the world. It gives an insight into critical factors that are predictive of number of deaths- the ultimate measure of health systems resilience. The study echoes the viewpoints of several reports that suggest that more robust and valid indicators are required to assess the performance of health systems, those that will truly guide the countries to be better prepared for any crises that may come up in future.

\section{Abbreviations:}

GHS: Global Health Security, CEST:Central European Summer Time, WHO: World Health Organisation, GDP: Gross domestic product, NHI: National Health Insurance, and UHC: Universal health coverage.

\section{Declarations:}

\section{Ethics approval and consent to participate:}

Not applicable because the analysis is based on analysis of secondary data available in public domain

\section{Consent for publication}

The manuscript does not contain any individual person's data or images.

\section{Availability of data and materials}

The study is based on analysis of secondary data available in public domain

\section{Abbreviations:}

GHS: Global Health Security, CEST:Central European Summer Time, WHO: World Health Organisation, GDP: Gross domestic product, NHI: National Health Insurance, and UHC: Universal health coverage.

\section{Competing interests:}

The authors declare that they have no competing interests. 


\section{Funding:}

None

\section{Authors' contributions:}

SBN conceptualised the study, analysed the results and drafted the manuscript; SP analysed and interpreted the data; PGS interpreted the data and findings, and SS compiled the data and contributed towards literature review. All authors read and approved the final manuscript.

Acknowledgements: We would like to acknowledge Dr Pankaj Talreja, Assistant Professor, International Institute of Health Management Research (IIHMR), New Delhi, India for reviewing the draft manuscript.

\section{References:}

1. WHO: COVID-19 Weekly Epidemiological Update.. In: https://wwwwhoint/publications/m/item/weekly-epidemiological-update-on-covid-19--21september-2021. Edited by WHO, vol. 2021. Geneva: WHO; 2021.

2. Haldane V, De Foo C, Abdalla SM, Jung A-S, Tan M, Wu S, Chua A, Verma M, Shrestha P, Singh S et al: Health systems resilience in managing the COVID-19 pandemic: lessons from 28 countries. Nature Medicine 2021, 27(6):964-980.

3. Neogi SB, Preetha GS: Assessing health systems' responsiveness in tackling COVID-19 pandemic. Indian J Public Health 2020, 64(Supplement):S211-s216.

4. Fernandes G: Overhauling health systems. In. Edited by https://www.imf.org/external/pubs/ft/fandd/2020/09/pdf/overhauling-health-systemsfernandes.pdf, vol. 2021; 2020.

5. WHO: The Global health observatory: explore the world of health data. In: Global health observatory. Edited by https://www.who.int/data/gho, vol. 2020. Geneva: World Health Organization; 2020.

6. Global Health Scurity Index In: GHS Index. vol. 2020. USA: NTI; Johns Hopkins Bloomberg School of Public Health; 2019.

7. El Bcheraoui C, Weishaar H, Pozo-Martin F, Hanefeld J: Assessing COVID-19 through the lens of health systems' preparedness: time for a change. Globalization and Health 2020, 16(1):112.

8. Kaiser M, Chen AT, Gluckman P: Should policy makers trust composite indices? A commentary on the pitfalls of inappropriate indices for policy formation. Health Res Policy Syst 2021, 19(1):40.

9. Kentikelenis A, Seabrooke L: Organising knowledge to prevent global health crises: a comparative analysis of pandemic preparedness indicators. BMJ Glob Health 2021, 6(8).

10. Abbey EJ, Khalifa BAA, Oduwole MO, Ayeh SK, Nudotor RD, Salia EL, Lasisi O, Bennett S, Yusuf HE, Agwu AL et al: The Global Health Security Index is not predictive of coronavirus pandemic responses among Organization for Economic Cooperation and Development countries. PLOS One 2020, 15(10):e0239398. 
11. Alfaro M, Muñoz-Godoy D, Vargas M, Fuertes G, Duran C, Ternero R, Sabattin J, Gutierrez S, Karstegl N: National Health Systems and COVID-19 Death Toll Doubling Time. Frontiers in Public Health 2021, 9(888).

12. Trends in future health financing and coverage: future health spending and universal health coverage in 188 countries, 2016-40. Lancet 2018, 391(10132):1783-1798.

13. Lal A, Erondu NA, Heymann DL, Gitahi G, Yates R: Fragmented health systems in COVID-19: rectifying the misalignment between global health security and universal health coverage. The Lancet 2021, 397(10268):61-67.

14. Officials OJNoSBaH: Performance measurement systems in the health sector and their budgetary implications. In: 7th Meeting of the OECD Joint Network of Senior Budget and Health Officials (14-15 February, 2019). Edited by Centre OC. Paris: DIRECTORATE FOR EMPLOYMENT, LABOUR AND SOCIAL AFFAIRS PUBLIC GOVERNANCE DIRECTORATE; 2019.

15. Measuring universal health coverage based on an index of effective coverage of health services in 204 countries and territories, 1990-2019: a systematic analysis for the Global Burden of Disease Study 2019. Lancet 2020, 396(10258):1250-1284.

16. Barasa E BS, Rao K, Goodman C, Gupta I, Hanvoravongchai P, James C MD, Witter S, Hanson K: Health financing in response to COVID-19: An agenda for research.. In. Edited by https://healthsystemsglobal.org/wp-content/uploads/2020/12/COVID-19-Health-financingresearchagenda_22-Nov-2020-final.pdf; 2020.

17. OECD: Strengthening health systems during a pandemic: The role of development finance. In: Tackling Coronavirus (COVID-1919): contributing to a global effort. Edited by read.oecdilibrary.org/view/?ref=134_134620-xueji119ph\&tit, vol. 2021; 2020. 